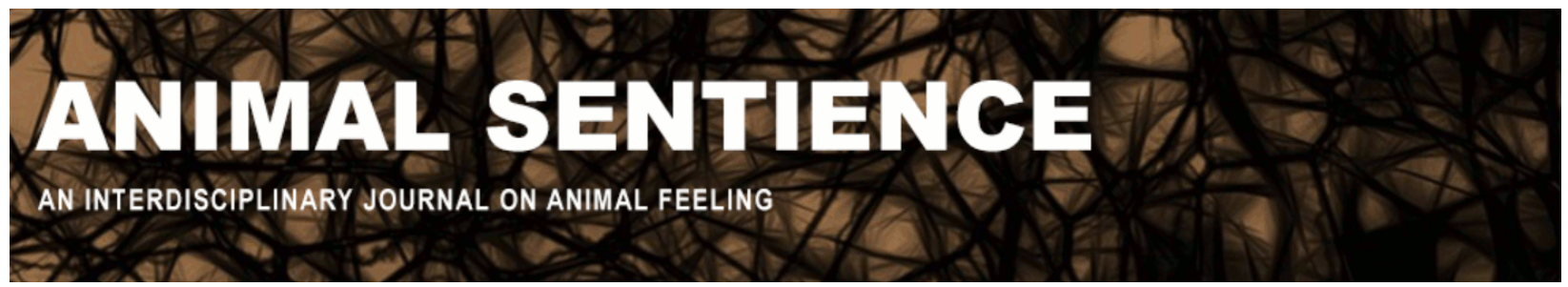

King, James (2019) Adding sheep to the spectrum of comparative psychology. Animal Sentience 25(33)

DOI: $10.51291 / 2377-7478.1479$

Date of submission: 2019-06-06

Date of acceptance: 2019-06-10

(c)

This article has appeared in the journal Animal

Sentience, a peer-reviewed journal on animal

cognition and feeling. It has been made open access,

free for all, by WellBeing International and deposited

in the WBI Studies Repository. For more information,

please contact

wbisr-info@wellbeingintl.org.

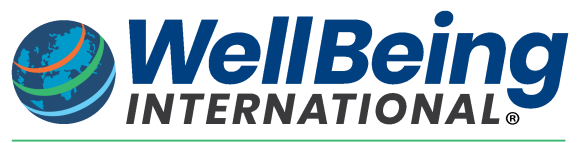

SOLUTIONS FOR PEOPLE, ANIMALS AND ENVIRONMENT 


\title{
Adding sheep to the spectrum of comparative psychology
}

\author{
Commentary on Marino \& Merskin on Sheep Complexity
}

\author{
James King \\ Department of Psychology \\ University of Arizona
}

\begin{abstract}
Marino \& Merskin's comprehensive review of cognitive complexity in sheep is a laudable and important contribution to comparative psychology. It is also valuable because it shows promising directions for future research on this neglected species. The relatively small number of neurons in the bovid cerebral cortex indicates that sheep cognitive performance on traditional measures of complex learning is limited. Nevertheless, the social and emotional complexity of sheep underscores the importance of further research into domains including personality and psychological well-being.
\end{abstract}

James King is Professor Emeritus of Psychology at the University of Arizona. His research has focused on primate behavior, including complex learning; behavioral laterality; and most recently, personality and lifespan in great apes. Website

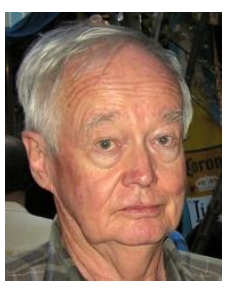

1. The value of comparative research. Comparative psychology has traditionally focused on a small number of different species. This restricted range of species has not changed dramatically since Beach's (1950) survey showing that pigeons, mice, and rats comprised virtually all the species used in comparative psychology research. Later surveys comparing species usage between 1983 and 1989, and 2010 and 2015, showed a decrease in the proportion of psychological studies on nonhuman species. Within the nonhuman literature, there was a marked decline in the use of rodents and an increase in the use of primates. Proportions of other species remained small (Stevens, 2017).

Marino \& Merskin's (2019) (M\&M) valuable target article is an important step in enlarging the domain of comparative study beyond primates and rodents to the artiodactyls. Many comparative psychologists would be surprised at the extent of past research on sheep. A significant but often unappreciated benefit of comparative studies is that they allow testing of the comprehensiveness of human-based findings across other species (Stevens, 2017), a goal consistent with an evolutionary perspective on human behavior. M\&M's paper includes several examples.

2. Neurological considerations. Recent evidence shows that the cognitive ability of animals is influenced more by the number of neurons in the neocortex or palladium than by the weight or size of the neocortex (Herculano-Houzel, 2016, 2017). The most dramatic example of the disconnect between these two types of measures is seen in corvid brains that have neuron counts 
in the palladium comparable to those in the monkey neocortex despite the large difference in the sizes of the corvid and primate brains (Oikowicz et al., 2016). The remarkable cognitive performance of corvids is consistent with these high neuron counts (Wright, 2017). Artiodactyls have relatively large brains featuring a highly convoluted neocortex. However, the neuron density and cell counts are relatively low (Kazu et al., 2014), indicating that we should not expect them to display surprising levels of cognitive performance and social intelligence.

3. Cautions. Although M\&M's review includes some impressive abilities of complex learning and face perception by sheep, there is occasional overemphasis of comparisons with human and nonhuman primates. For example, sheep performance in attentional set-shifting (Morton \& Avanzo, 2011) was described as being on a par with primates although the only similarity between sheep and primates was that extra-dimensional shifts were more difficult than intra-dimensional shifts. Likewise, the "exclusion performance" test (Nawroth et al., 2014), described as typically used with primates, is more commonly called a delayed-response test and has been frequently used across many species. The sheep performance was not remarkable. M\&M's section on sheep responses to mirrors also indicated that repetitive head movements and possible contingency checking were the only responses of sheep exposed to their mirror images (McBride et al., 2015). This is far short of evidence of using mirrors for finding objects or for self-recognition.

4. Personality. M\&M described several areas in which data from sheep would be useful in future comparative research. One of these is the issue of individual differences in personality. They describe examples in which fundamental temperamental dimensions, including boldness and gregariousness, are associated with behavioral measures such as foraging decisions. The range of personality ratings could be greatly expanded by using a broad range of personality descriptive adjectives or short descriptions of personality traits measured in humans. Items used to define the human Big Five dimensions are examples. This approach does not in any way imply that the human Big Five personality structure describes sheep personality: Almost certainly it would not. Personality structure specific to sheep would emerge from ratings of individual differences among sheep. This approach has been used successfully with monkeys and apes (Weiss, 2018) as well as fallow deer (Bergvall et al., 2011). In addition, this approach has been used successfully to measure the well-being of chimpanzees. Reluctance to use this expanded approach to personality measurement is often based on the charge of the old bugbear of anthropomorphism. However, ample evidence now exists supporting the scientific value of trait ratings. Personality ratings have reliabilities equal to or greater than comparable ratings for humans; they also have good construct validity (Weiss, 2018). Furthermore, there is direct evidence that these rating are not direct anthropomorphic projections of humans (Weiss et al., 2012).

In summary. Many enticing possibilities exist for unraveling the capabilities of the sheep mind. M\&M's review will inspire future investigations. 


\section{References}

Beach, F. A. (1950). The snark was a boojum. American Psychologist, 5(4), 115-124.

Bergvall, U. A., Schäpers, A., Kjellande, P., \& Weiss, A. (2011). Personality and foraging decisions in fallow deer (Dama dama). Animal Behaviour, 81(1), 101-112.

Herculano-Houzel, S. (2016). The human advantage: A new understanding of how our brain became remarkable. Cambridge, MA: The MIT Press.

Herculano-Houzel, S. (2017). Number of neurons as biological correlates of cognitive capability. Current Opinion in Behavioral Sciences, 16, August, 1-7.

Kazu, R. S., Maldonado, J., Mota, B., Manger, P. R., \& Herculano-Houzel, S. (2014). Cellular scaling rules for the brain of Artiodactyla include a highly folded cortex with few neurons. Frontiers in Neuroanatomy, 8, 128.

Marino, L., \& Merskin, D. (2019). Intelligence, complexity, and individuality in sheep. Animal Sentience 25(1).

McBride, S., Perentos, N., \& Morton, A. J. (2015). Understanding the concept of a reflective surface: Can sheep improve navigational ability through the use of a mirror? Animal Cognition, 18(1), 361-371.

Morton, A. J., \& Avanzo, L. (2011). Executive decision making in the domestic sheep. PLoS One, 6(1), e15752.

Nawroth, C., vov Borell, E., \& Langbein, J. (2014). Exclusion performance in dwarf goats (Capra aegagrus hircus) and sheep (Ovis orientalis aries). PLoS One, 9(4) e93534.

Oikowicz, S., Kocourek, M., Lučan, R. K., Porteš, M., Fitch, W. T., Herculano-Houzel, S., \& Němec, P. (2016). Birds have primate-like numbers of neurons in the forebrain. PNAS: Proceedings of the National Academy of Sciences of the United States of America, 113(26), 7255-7260.

Stevens, J. R. (2017). Replicability and reproducibility in comparative psychology. Frontiers in Psychology, 8, 1-6.

Weiss, A. (2018). Personality traits: A view from the animal kingdom. Journal of Personality, 86(1), 12-22.

Weiss, A., Inouve-Murayama, M., King, J. E., Adams, M. J., \& Matsuzawa, T. (2012). All too human? Chimpanzee and orang-utan personalities are not anthropometric projections. Animal Behaviour, 83(6), 1355-1365. 